\title{
Stressor Appraisal on a Pathway to Health: The Role of the Sense of Coherence
}

\author{
Maurice B. Mittelmark
}

\section{Introduction}

An extensive literature shows that the sense of coherence (SOC) is related statistically to a host of behaviours with implications for illness and health (Eriksson \& Lindström, 2006, 2007; Mittelmark et al., 2017). To make sense of the statistical associations, we require research on the mechanisms by which the SOC is involved in health development (Super et al., 2016). What makes the connection? What is in the black box?

This chapter is about Aaron Antonovsky's answer: the SOC influences how a person appraises and reacts to stressors. This process occupies a critical place along the pathway from the SOC to behaviour.

We begin with definitions of two key terms (Antonovsky, 1979, p 72):

- A routine stimulus is one to which the organism can respond more or less automatically, which poses no problem in adjustment.

- A stressor is a stimulus making a demand from an organism's internal or external environment that upsets its homeostasis, restoration of which depends on a nonautomatic and not readily available energy-expending action.

Research reveals that the SOC develops during the entire life course (Silverstein \& Heap, 2015), influenced by the accumulating experience of encountering, appraising and reacting to stressors, and experiencing sequela. How one experiences stressors today is, therefore, affected by how one experienced stressors previously. Which stressors one encounters, how one appraises them and how one reacts is recursive. For example, one's first encounter with a dog as a child can help determine if and how dogs will tend to be encountered in the future (one might be inclined to seek the

M. B. Mittelmark ( $₫)$

Department of Health Promotion and Development, Faculty of

Psychology, University of Bergen, Bergen, Norway

e-mail: maurice.mittelmark@uib.no companionship of dogs with joy, to shun them with fear or to ignore them). One's appraisal of and reactions to dogs, and the reactions of dogs, adds to one's accumulating experience. Feedback from experience is a critical factor in shaping one's future appraisals.

The resources one was able to engage while experiencing one's first dog (perhaps a parent's encouraging words) impacts one's appraisal, adds to one's accumulating coping resources and ultimately influences the development of one's SOC. One's store of general and specific resistance resources (GRRs and SRRs, see Chaps. 12 and 13) and one's ability to engage them in coping also develop. One's growing experience using resources affects the development of the SOC.

\section{The Central Role of the Brain}

Appreciative of the role of the brain in coping with stressors, Antonovsky wrote:

Whether the source of the stressors is the internal or external environment, whether they are daily hassles, acute or chronic and endemic, whether they are imposed upon one or freely chosen, our lives are replete with stimuli to which we have no automatic, adequate adaptive response and in the face of which we must respond. The message to the brain... is clear: You have a problem. The nature of the problem is dual, consisting of (a) the problem-solving or instrumental issue and (b) the issue of the regulation of emotion. Tension, then, reflects the recognition in the brain that some need one has is unfulfilled, that a demand on one has to be met, and that one must do something if one is to realise a goal. (Antonovsky, 1990a, p. 35)

By 'problems', Antonovsky meant exposure to both unpleasant and pleasant stimuli that are salient enough to evoke appraisal (Antonovsky, 1990a, p 136):

- The worker just informed that she is to be laid off.

- The woman enduring sexual harassment from her boss.

- The woman giving birth to her first child.

- The person just promoted to a much more responsible position at work.

- The couple planning their wedding. 
Unpleasant or pleasant, a salient problem induces one to appraise one's situation.

As Antonovsky understood it, the appraisal process may be conscious, barely conscious and even subconscious, with multiple considerations simultaneously unfolding in a jumble, often with great rapidity:

\begin{abstract}
Although it has taken me many words to discuss the processes... this does not necessarily reflect the time span involved in confronting a stressor from its appearance until the moment one acts (or does not act) directly to deal with it. Nor is the process anywhere near as rational or cognitive as it may sound. The process may be most rapid and very largely unconscious. (Antonovsky, 1990a, p. 43)
\end{abstract}

The appraisal process leads to an appraisal outcome; do nothing or do something. We are bombarded continuously by stimuli that are salient enough to warrant appraisal, which is the nature of living (Antonovsky, 1987). What is meant by 'bombarded'? Consider the woeful student worrying over the exam next hour while cycling anxiously along a busy and dangerous thoroughfare to the university, uneasy about the threatening and lightning-filled storm clouds approaching from the horizon and feeling desperate about covering the week's rent, overdue for several days already.

A description of the student's appraisal processes defies neat arrow and box diagrams. A description of the student's appraisal outcomes is more feasible, and this is the subject of extensive stress and coping literature spanning three decades (Lazarus \& Cohen, 1977; Lazarus \& Folkman, 1984; Lazarus, 1984; Scherer et al., 2001; Feldman et al., 2004; Aldwin \& Park, 2004; Cheng \& Cheung, 2005; Sideridis, 2006; Searle \& Auton, 2015). This rich and fascinating literature was an important background for Antonovsky's work, and he brought to it his unique perspective on the role of the SOC in coping with stressors.

\section{Stimulus and Stressor Appraisal on the Pathway to Health}

Antonovsky proposed that on the pathway to health, relatively strong- compared to weak-SOC persons tend to appraise and react to stimuli and stressors differently. In his writings, Antonovsky offered arguments for a series of propositions about how the strength of the SOC affects appraisal (Antonovsky, 1987, 1990a, 1990b, 1990c, 1992). In the section below, I refer to his propositions as hypotheses.

Antonovsky's most extensive treatment of pathways leading to health appeared in Chap. 6, Unraveling the Mystery of Health (1987). In a later chapter, he revised and updated material from the 1987 book (Antonovsky, 1990a). Here, we rely most on the 1990 publication, as it was Antonovsky's most advanced exposition on the role of the SOC in stimulus and stressor appraisal.

The idea of stimulus and stressor appraisal stages is of core importance in the stress and coping literature. Antonovsky's central contribution to this literature was to discuss how the strength/weakness of the SOC affects appraisal, action and reaction to feedback, at primary, secondary and tertiary stages (see Table 10.1). The right-hand column in Table 10.1 presents snapshots of Antonovsky's expectations (hypotheses) about how the SOC affects stimulus and stressor appraisal, and this is discussed in detail below.

H1 'The person with a strong SOC is more likely to define stimuli as nonstressors, and to assume that he or she can adapt automatically to the demand than one with a weak SOC. In this way, the former will not experience tension, nor see it transformed into stress'. (Antonovsky, 1990a, p 37)

Table 10.1 The role of strong compared to weak SOC in stimulus and stressor appraisal, action and reaction to feedback

\begin{tabular}{|c|c|c|}
\hline Appraisal stage & Appraisal and coping processes & The strong-SOC person is more likely to... \\
\hline $\begin{array}{l}\text { Primary appraisal I } \\
\text { Stimulus encountered that calls for focused } \\
\text { consideration }\end{array}$ & $\begin{array}{l}\text { Non-stressor (does not pose demands that } \\
\text { exceed resources) or. } \\
\text { Stressor (state of tension created). }\end{array}$ & $\begin{array}{l}\text { Experience the stimulus as non-stressor. } \\
\text { Assume that stimulus demands can be met } \\
\text { 'automatically'. }\end{array}$ \\
\hline $\begin{array}{l}\text { Primary appraisal II } \\
\text { Stimulus perceived as a stressor }\end{array}$ & $\begin{array}{l}\text { Endangering one's well-being. } \\
\text { Being positive. } \\
\text { Being benign/irrelevant. }\end{array}$ & $\begin{array}{l}\text { Experience the stressor as benign/irrelevant/ } \\
\text { positive. } \\
\text { Feel confident that the tension will soon } \\
\text { dissipate. }\end{array}$ \\
\hline $\begin{array}{l}\text { Primary appraisal III } \\
\text { Stressor perception and regulation of } \\
\text { stressor-induced emotion }\end{array}$ & $\begin{array}{l}\text { Happy, non-conflictual and not dangerous. } \\
\text { Unhappy, conflictual or/and dangerous. }\end{array}$ & $\begin{array}{l}\text { Understand the instrumental coping challenge. } \\
\text { Experience the stressor as happier, less } \\
\text { conflictual and less dangerous. }\end{array}$ \\
\hline $\begin{array}{l}\text { Secondary appraisal } \\
\text { Coping }\end{array}$ & Moves from perception to action. & Mobilise the most appropriate GRRs / SRRs. \\
\hline $\begin{array}{l}\text { Tertiary appraisal } \\
\text { Feedback and learning }\end{array}$ & $\begin{array}{l}\text { Experiences coping attempts and outcomes. } \\
\text { Exposed to direct and indirect feedback. }\end{array}$ & $\begin{array}{l}\text { Elicit feedback and assess it. } \\
\text { Attend to signals. } \\
\text { Be willing to change course. } \\
\text { Experience that GRRs are strengthened. } \\
\text { Experience that the SOC is 'fortified'. }\end{array}$ \\
\hline
\end{tabular}




\section{Primary Appraisal I}

H1 has hardly received empirical scrutiny. It is hard to conceive how quantitative research on the SOC and appraisal behaviour could uncover findings that support or refute H1. It seems that only qualitative research could produce the needed data, using in-depth interviews to document strongand weak-SOC persons' lifelong experience, including instances of encountering stimuli that might, but do not necessarily provoke appraisal of a stimulus as a stressor. It is easy to think up a long list of such stimuli, but it is not easy to imagine how the researcher could account for context effects. Consider, for example, two drivers encountering a very busy roundabout while driving in heavy city traffic. Regardless of SOC, the driver on a casual Sunday drive might blithely disregard the potential stress in the situation, while the driver delivering his labouring wife to the hospital might well break out in a cold sweat. Regardless of what differences the researcher might find regarding SOC levels, the probable conclusion would likely depend on the context. If this cautious analysis has merit, we might just as well dismiss $\mathrm{H} 1$ as untestable.

H2 'The strong-SOC person, having considerable experience in encountering stimuli that initially seem to be stressors but soon turn out not to be problematic, without any particular investment of energy on his or her part, is more likely, at the primary appraisal-II stage, to define a stressor as benign or irrelevant, to feel confident that the tension will quickly dissipate" (Antonovsky, 1990a, p 37).

\section{Primary Appraisal II}

Primary appraisal II is invoked when stimuli are perceived as stressors

'...endangering one's well-being, positive, benign or irrelevant... to perceive a stressor as benign or irrelevant is to define it as of little consequence for one's life... it is assumed that the tension will soon be dissipated'. (Antonovsky, 1990a, p 37)

However, Antonovsky warned of a potential downside of a strong-SOC person's tendency to define a stressor as benign or irrelevant. He mentioned delay in seeking medical treatment (a problem of global proportion, see Wechkunanukul et al., 2017) writing, 'there is a danger that the strong-SOC person will at times deceive himself or herself'. Antonovsky equivocates, suggesting that self-deception is in some instances less likely to be the case for the strong-SOC, compared to the weak-SOC person, with the former tending to be more realistic in not worrying about tension-arousing stimuli (like chest and other pains that can be a warning of a heart attack).
This equivocation is equivalent to saying 'it depends' and complicates any effort to examine empirically $\mathrm{H} 2$. To the degree that a person's previous experience is a factor at the appraisal II stage, the researcher would wish to know the person's history. As a methodological issue, this suggests the importance of qualitative approaches to the study of Antonovsky's appraisal hypotheses to uncover information about the respondent's encounters with stressors that did and did not induce coping (see Chap. 54).

Antonovsky concludes his discussion of appraisal I and II provocatively, writing that 'if, then, the strong-SOC person is advantaged..., such advantage is relatively unimportant' because life is filled with stressors that cannot be shrugged aside.

Regarding the availability of data suitable to test $\mathrm{H} 2$ and the feasibility and importance of testing $\mathrm{H} 2$, we might well come to the same conclusion as for H1. It seems stress researchers have little interest in instances where a person can shrug off a stressor lightly. We might as well agree with Antonovsky that the proposition behind this hypothesis is 'relatively unimportant'.

Or we may wish to follow Amirkhan and Greaves (2003) in exploring Antonovsky's writings for new theoretical ideas about primary appraisal mechanisms that might explain the link between the SOC and health. They discuss three possibilities: perceptual, cognitive and behavioural mechanisms. As to perception, they suggest that:

\footnotetext{
'... while all people sort stimuli according to intensity, size, shape, and other properties, perhaps those with a strong SOC also classify according to the perceived meaningfulness of the stimulus. When confronted with problems, then, strong SOC individuals might view some or all of these as coherent, while other people might simply not attend to this property'. (ibid, p 33)
}

They do not speculate how the differential perception of a stimulus by strong- and weak-SOC people might lead to different primary appraisal outcomes. However, they do discuss the possibility of a reciprocal relationship with the SOC influencing stimulus perception that influences the SOC that influences perception, and so on. As a result, over the long term, strong-SOC persons may be more likely to perceive coherence and meaningfulness and experience SOC strengthening.

Regarding cognition, Amirkhan and Greaves (2003) point out the possible relevance of attribution theory (Weiner, 2010), suggesting that attributes of stimuli are important in differentiating strong- and weak-SOC persons' appraisals. They mention the possibility that one attribution dimension is the degree of coherence of a stimulus' causes. Compared to weak-SOC persons, strong-SOC persons encountering a stressor may have the knack of analysing the degree of coherence among causes behind the stressor. Stressors judged to 
have coherent causes may produce less emotional distress or more motivated responses.

Regarding behaviour, Amirkhan and Greaves (2003) point to the possibility that the SOC's strength determines at least partly coping choices, independent of the effects of appraisal processes. In other words, perhaps strong-SOC persons have a more marked propensity to focus on and rectify problems compared to weak-SOC persons.

A series of laboratory and field studies undertaken to explore these mechanisms revealed

'.... perceptual process, that was pervasive and yet subtle in nature. A strong SOC seems to work much like rose-colored glasses that one has grown accustomed to wearing: Although not conscious of their presence, one still benefits by the pleasant tint that they provide'. (Amirkhan \& Greaves, 2003)

Amirkhan and Greaves' (2003) idea about rose-coloured glasses indicates a subconscious level of stimuli engagement and not the conscious and near-subconscious levels that held Antonovsky's attention. This suggests a line of inquiry that may prove illuminating, although not directly relevant to this chapter's theme.

Even if the work just discussed does not directly address Antonovsky's hypotheses about stimulus appraisal, it may illuminate ways to improve coping effectiveness. Amirkhan and Greaves' (2003) ideas about perceptual, cognitive and behavioural primary appraisal mechanisms, and subconscious processing, are certainly deserving of further exploration.

Regardless of the SOC's strength, health benefits might accrue if one learns to deploy coping responses in a manner consonant with that of strong-SOC persons.

H3 The strong-SOC person is "more likely to appraise a stressor as happier, as less conflictful, or less dangerous than one with a weak SOC'. (Antonovsky, 1990a, p 39-40).

\section{Primary Appraisal III}

Primary appraisal III is focused on how the strong-SOC person perceives and regulates the emotion induced by a stressor and apprehends the instrumental challenge of coping with the stressor.

This is a compound statement (happier, less conflictual and less dangerous); are underlying dimensions thought to link these appraisal possibilities? The answer seems to be no. One can easily imagine a questionnaire in which the respondent is asked to consider a particular stressor and rate it on three separate dimensions: happy-unhappy, conflictual-not conflictual and dangerous-not dangerous.

Antonovsky describes how a 'happy' stressor may arouse different emotions: two widowers meet attractive women; the widower with a strong SOC feels hope and excitement, while the widower with a weak SOC feels hopelessness and apathy. The differences in emotion feed differences in reacting instrumentally. Meeting the attractive woman is, in SOC terms, more meaningful to the strong- than to the weak-SOC widower, or as Antonovsky writes:

\begin{abstract}
'The strong-SOC person perceives the same problems, but with greater clarity, more specificity, and more precise differentiation. The problems... are seen as more comprehensible and manageable...[and] as challenges rather than as burdens... The strong-SOC person, encountering a stressor, is more likely to be capable of introducing order and meaning into the situation... The strong-SOC person... has a head start. Before taking action, he or she has mobilised resources to confront the stressor. By contrast, the weak-SOC person, confused and devoid of the desire to cope, tends to give up at the outset'. (Antonovsky, 1990a, p 40-41).
\end{abstract}

Brady (2017) undertook a meticulous examination of appraisal à la H3. She studied 591 American graduate students with paid employment alongside studies and adults who were full-time employees working at least 34 hours per week. Brady administered the SOC-29 Orientation to Life Questionnaire (Antonovsky, 1993) and the Work-Related Sense of Coherence (Work-SOC) of Bauer and Jenny (2007). She also assessed the prevalence of 17 stressors in a participant's workplace, and administered scales measuring primary appraisal propensities (Searle \& Auton, 2015) and threat (Feldman et al., 2004):

- Challenge appraisal of a stressor that opens for personally meaningful gain having the potential to engage the person (Cavanaugh et al., 2000).

- Hindrance appraisal of a stressor perceived to restrict or obstruct opportunities for personally meaningful gains or to interfere with work achievement (Cavanaugh et al., 2000).

- Threat appraisal of a stressor perceived as holding risk for personal harm or loss (Tuckey et al., 2015).

Challenge appraisal is somewhat akin to Antonovsky's happiness dimension. Hindrance appraisal is akin to Antonovsky's conflict dimension. Threat appraisal is to a reasonable degree akin to Antonovsky's danger dimension. Therefore, the measures of challenge, hindrance and threat appraisal in Brady's research are of some utility in exploring $\mathrm{H} 3$.

Brady hypothesised that (a) there is a positive relationship between SOC and tendency to appraise work stressors as challenges; (b) there is a negative relationship between SOC and tendency to appraise work stressors as hindrances and (c) there is a negative relationship between SOC and tendency to appraise work stressors as threats. 
Her analysis of correlation coefficients among the SOC and the appraisal variables confirmed the hypotheses, both for the SOC-29 and the work-SOC measures. She concluded:

\begin{abstract}
...stronger SoC are more likely to appraise stressors as challenges and that individuals with a weaker $\mathrm{SoC}$ are more likely to appraise stressors as hindrances and threats. Similarly, the initial results suggest that individuals with a stronger Work-SoC are more likely to appraise stressors as challenges and individuals with a weaker Work-SoC more likely to appraise stressors as hindrances and threats.
\end{abstract}

Brady's structural equation modelling with the same data revealed thought-provoking findings on the SOC components comprehensibility, manageability and meaningfulness:

- Individuals who viewed their world as more comprehensible were less likely to appraise stressors in their work environment as challenges and as threats.

- Individuals who viewed their world as more manageable were more likely to appraise stressors in their work environment as hindrances.

- Individuals who viewed their world as more meaningful were less likely to appraise stressors in their work environment as threats.

These results on the SOC components are provocative since they do not take cognisance of Antonovsky's assertion that, from a theoretical standpoint, the SOC components are linked inextricably. Still, the findings on comprehensibility and meaningfulness seem to offer support to $\mathrm{H} 3$, while the finding on manageability does not. The overall pattern of results from this study does seem to support $\mathrm{H} 3$.

This study is of particular value because it included targeted stimuli appraisal measures, rare in the stress and coping and the salutogenesis literatures.

Other findings relevant to $\mathrm{H} 3$ come from a series of studies in Israel and Greece:

- Braun-Lewensohn et al. (2011) measured cognitive appraisal - feelings of danger - in 138 teenagers living in Southern Israel cities and villages in January 2009, a period of violent hostilities and missile attacks on the teenagers' communities.

- Braun-Lewensohn and Al-Sayed (2018) measured appraisals of danger in 110 Syrian adolescents, boys and girls, living in a European refugee camp for between 6 months and 2 years. Besides the experience of severe social disruption in Syria that resulted in relocation, these youth suffered the trials and tribulations of living an extended period as refugees.

- Braun-Lewensohn et al. (2019) measured cognitive appraisal (feelings of danger) in 110 Syrian refugee women (ages 19-70) living in a camp in Greece. In this study, individual SOC and community SOC (BraunLewensohn et al., 2011) were assessed.

The three papers just cited reported extensive and noteworthy findings on coping strategies and adaptation. But for the present purposes, the as-yet unpublished findings of relevance are these: in all three samples of youth and adults living in distressful condition, strong-SOC participants reported significantly lower levels of feeling danger than weak-SOC participants (Braun-Lewensohn, personal communication).

These studies are of particular interest because they do not focus on the appraisal of specific instances of experiencing a stimulus but rather a backdrop of stress-inducing stimuli over an extensive period. The findings in all samples - that SOC level differentiated cognitive appraisal (feeling danger) - add a new dimension to the test of H3. Antonovsky's analysis and proposition about primary appraisal III referred to one's experience of 'a stressor', not a widespread pattern of social stress (a context of stress). These studies not only provide support for $\mathrm{H} 3$; they extend our consideration of primary appraisal III to contextual stress. Braun-Lewensohn et al. (2019) conclude:

... it is very important to strengthen the SOC and ComSOC [community SOC] of refugee women, to enable them to better adapt when confronted with a variety of stressful situations. It is also important that women be integrated into societal processes, in order for them to feel in control of their lives and to strengthen their senses of manageability and comprehensibility.

H4 The person with a strong SOC 'chooses from the repertoire of generalised and specific resistance resources at his or her disposal what seems to be the most appropriate combination... it is in the actual mobilisation of what seems to be the most appropriate resource or combination of resources in the face of the given stressor that the true advantage of the strong-SOC person [over the weak-SOC person] comes to the fore." (Antonovsky, 1990a, p 42).

\section{Secondary Appraisal}

Antonovsky moves from stressor perception to action with this question: How does the strong-SOC person resolve the instrumental problem? With this, we come to the subject of coping, and as Antonovsky adamantly states, in the salutogenic model, coping does not refer to a specific coping style (italics his). Stressors are many and varied, and so is coping.

A test of $\mathrm{H} 4$ would require the researcher to gather information on respondents' GRRs and SRRs, and which of these resources were mobilised in the past in response to particular 
stressors. The researcher would also need to make judgements about the most appropriate resource or combination of resources in each respondent's armamentarium that the respondent could have called on in the face of the given stressors. This would need to be followed by comparing strong- and weak-SOC respondents' actual engagement of resources.

As far as I am aware, no such study has been reported in the literature. This is not surprising since it is hard to conceive a practical research methodology to collect the needed data. At the very least, the researcher would need to gather copious amounts of interview data from each respondent, then conduct within-case analyses, followed by cross-case analyses. The research effort would be strenuous indeed, and conclusions would be decidedly tenuous. We might just as well conclude that such studies are infeasible, or at least too demanding, to be worth the effort to investigate $\mathrm{H} 4$.

H5 'The person with a strong SOC... will tend to focus on the instrumental parameters of the problem, and will see as the challenge the question of what resources can be mobilised to meet the problem... The person with the weak SOC, seeing the stressor only in its burdensome aspects, will tend to focus on the emotional parameters, on handling the anxiety and unhappiness brought into being by the stressor." (Antonovsky, 1990a, p 43).

H5 receives some support. In research by GambettaTessini et al. (2016), 2049 oral health professional students in Australia, New Zealand and Chile completed the SOC13 and Brief Coping Orientation for Problems (COPE) Questionnaires in English and Spanish (Chile). COPE gathers self-report data on coping strategies that the respondents have engaged in, categorised as adaptive coping (e.g. active coping, planning, positive reframing and seeking support) or maladaptive coping (e.g. denial, venting and substance abuse). Compared to weak-SOC respondents, strong-SOC respondents reported significantly more adaptive coping strategies (active coping $r=0.14$, and positive reframing $r=0.13$ ). Conversely, compared to weak-SOC respondents, strong-SOC respondents reported significantly fewer maladaptive coping strategies (self-distraction $r=-0.12$; denial $r=-024$; substance use $r=-0.22$; behavioural disengagement $r=-026$; venting $r=-0.24$ and selfblame $r=-0.0 .38$ ). These results suggest that strong-SOC young people are perhaps more inclined to choose adaptive coping strategies than avoiding maladaptive strategies. While there is some evidence supporting H5, the most significant pattern in the data supports a moderating effect of the SOC on coping, but in a manifestation not precisely in synchrony with $\mathrm{H} 5$.

Several studies highly relevant to H5 have been undertaken in Poland.
Konaszewski and Kwadrans (2020) studied the relationship between SOC and coping styles in 210 juveniles in probation centres in Poland. SOC was measured using the Orientation to Life Questionnaire. Coping strategies were measured using a 48-item inventory measuring three coping styles: task oriented, emotion oriented and avoidance oriented. In the probation sample, a strong SOC was significantly positively associated with a task-oriented style $(r=0.29)$ and significantly negatively associated with an emotion-oriented style $(r=-0.27)$. Analyses of SOC components (comprehensibility, manageability and meaningfulness) revealed the same pattern of results. Thus, there is support for H5 and consistency with Gambetta-Tessini et al. (2016) results. This adds weight to the earlier suggestion for a corollary to $\mathrm{H} 5$ - the hypothesis that strong-SOC persons are more inclined to avoid maladaptive strategies than weakSOC persons.

Konaszewski et al. (2019), using the same instruments as above, observed that strong-SOC university students were significantly more likely than weak-SOC students to report using a stress coping style focused on tasks $(r=0.38)$ and significantly less likely to use a style focused on emotions $(r=-0.62)$.

Kotowska and Weber-Nowakowska (2019) compared coping styles in 50 orthopaedic surgery patients and 50 healthy controls. In both groups, strong-SOC participants were significantly more likely than weak-SOC participants to report active coping, acceptance of the problem, positive reframing and planning, and significantly less likely to report self-distraction, denying problems, discharging frustration, ceasing activity and engaging in self-blame. The study also examined styles of coping for the SOC components and found the same pattern. The two study groups did differ (regardless of SOC strength) in some coping styles, but the overall pattern noted above was the dominant finding.

Also in Poland, Andruszkiewicz et al. (2017) studied 188 adults aged 60-89 years with diagnoses of chronic illness and accompanying pain. Participants with a strong SOC were significantly less likely than weak-SOC participants to report using a catastrophising coping style. In contrast, the strong- and weak-SOC participants did not differ in their reported use of distraction or turning to prayer/hope.

In yet another Polish study, Krok (2016) enrolled 212 adults aged 65-79 years and measured SOC and coping styles (task oriented, emotion oriented and avoidance oriented). Strong- compared to weak-SOC participants were significantly more likely to report task-oriented coping and significantly less likely to report emotion-oriented coping. There was no difference in the use of avoidance-oriented coping.

Moving to The Netherlands, Polhuis et al. (2020) collected SOC and interview data from 17 Dutch respondents with type 2 diabetes mellitus to explore how and why their 
eating practices developed after encountering turning points (stressors) for developing unhealthy or healthy eating. Examples of turning points for unhealthy eating were child neglect, losing a job and losing a parent. Examples of turning points for healthy eating were confrontations with ill health, becoming a parent and getting married. In this study, most strong-SOC respondents who had experienced a confrontation with ill health intended to engage in active coping (adhering to dietary guidelines). The qualitative study design did not permit statistical analysis of strong- compared to weak-SOC respondents' active coping. These findings are not consistent with an alternative expectation; strong-SOC persons may deny symptoms and delay taking action on medical problems. Antonovsky was well aware of this possibility but maintained that such self-deception was more likely to be the case for the weak- than for the strong-SOC person (Antonovsky, 1987, p 134).

In Sweden, Kristofferzon et al. (2018) enrolled 348 seriously ill chronic disease patients with a mean age of 69 and measured the SOC and two coping styles, emotion focused and problem focused. Strong- compared to weak-SOC participants were significantly less likely to report using problem-focused coping $(r=-0.24)$ and emotion-focused coping $(r=-0.45)$. This is consistent with H5 because the negative relationship between SOC and emotion-focused coping was stronger than the negative relationship between SOC and problem-focused coping.

Finally, Ngai (2019) enrolled 201 women in Hong Kong, ages 40-60, who underwent the menopausal transition. Ngai measured the SOC and coping styles, including adaptive coping (acceptance and humour) and maladaptive coping (venting, behavioural disengagement, self-distraction, selfblame, substance use and denial). Strong- compared to weak-SOC respondents were more likely to report using an adaptive coping style $(r=0.41)$ and significantly less likely to report using a maladaptive coping style $(r=-0.51)$.

H6 "The person with a strong SOC, long familiar with looking for feedback, will both elicit it and be capable of assessing it. With a weak SOC, once one's course is set, one tends to disregard signals that contradict the wisdom of the action chosen. There is no motivation to relinquish a course leading to a dead end and search for alternative courses of action. One goes on one's way blindly." (Antonovsky, 1990a, p 48)

\section{Tertiary Appraisal}

We come, then, to the final stage of the appraisal and coping process as the salutogenic model has it; that of applying resources to meet a stressor and the process of receiving and apprehending feedback and making course corrections. As for several of the other hypotheses discussed above, H6 seems to have attracted little attention from salutogenesis researchers. In the cases of $\mathrm{H} 1, \mathrm{H} 2$ and $\mathrm{H} 4$, this chapter has pondered reasons for researchers' neglect, such as methodological difficulties that seem to preclude the possibility of hypothesis testing. In the case of H6, the lack of data is disappointing. At a theoretical level, tertiary appraisal seems to be an essential aspect of learning to cope with stressors. Feedback should lead to strengthened SOC and the accumulation of GRRs and SRRs. The failure to engage in tertiary appraisal (not learning from experience) would, in theory, have opposite results: weak SOC and meagre access to resources. As Antonovsky put it,

The person with a strong SOC, long familiar with looking for feedback, will both elicit it and be capable of assessing it. With a weak SOC, once one's course is set, one tends to disregard signals that contradict the wisdom of the action chosen. There is no motivation to relinquish a course leading to a dead end and search for alternative courses of action. One goes on one's way blindly. (Antonovsky, 1990a, p 48)

Literature searches using Google Scholar and PubMed in 1979-2020 uncovered just one study directly relevant to H6 (Pijpker et al., 2018). This seminal report from the Netherlands recruited 481 Dutch nurses and caregivers in four residential care settings and one healthcare-related Dutch Facebook group. SOC was measured using the Dutch 13-item Orientation to Life Questionnaire. Feedback was measured using the Workplace Learning Processes Questionnaire (WLPQ). The investigators used factor analysis of the WLPQ to identify a scale measuring feedback (social learning), with these four items: reflecting with my colleagues on my actions, asking colleagues for advice, observing my colleagues and developing new ideas with my colleagues. The study also gathered data on GRRs in three categories: social support, meaning attached to work and job control. Strong SOC participants had significantly higher feedback scores compared to weak-SOC participants $(r=0.10 p<0.05)$. Based on the results of moderating and mediating analyses, the investigators concluded that a strong SOC fosters behaviour (learning) via feedback, a conclusion in line with H6.

\section{Discussion}

The salutogenesis literature abounds with the finding that the SOC's strength is related significantly to a plethora of proximal (behaviours) and distal (disease, health and well-being) endpoints. Researchers' conclusions are almost all in the form of 'persons with a strong-SOC are better off than persons with a weak-SOC'. One implication is that interventions to strengthen the SOC are needed. This handbook includes several chapters that describe ways to strengthen the SOC.

Regrettably, there is a lack of thinking and research about how to shape stressor appraisal to foster better health, regardless of SOC strength. Because stressor appraisal is theorised 
as the most proximal factor connecting the SOC and behaviour, this chapter alerts salutogenesis researchers to the idea that stressor appraisal, and not just the SOC, should be in focus in our intervention research.

Antonovsky's main ideas about strong versus weak SOC and appraisal of stimuli are summarised in the six hypotheses discussed in this chapter. Though Antonovsky writes about strong and weak SOC, he presumes the reader understands this is shorthand for referring to the SOC continuum's poles. He also assumes that the reader understands the enormous importance of culture and context in accessing resources and the possibility of their activation. He cautions that few people have a very strong SOC (conversely, we should understand that few people have a very weak SOC). Finally, he has warned against any tendency to assume that a strong SOC is good in and of itself, noting that a Nazi may well have a strong SOC (Antonovsky, 1986).

With these caveats in the back of our minds, what may we conclude from the present literature analysis?

Regarding H1 - At the stage when stimuli are appraised as non-stressors or stressors, no evidence of the importance of the SOC was uncovered in my search. H1 remains speculative, and I think it must remain so. It seems infeasible to study one's daily bombardment of stimuli and connect one's SOC strength to judgements about which stimuli are stressors. How a researcher might trace and record all relevant stimuli during a respondent's daily life is a mystery. $\mathrm{H} 1$ is interesting but untestable.

Regarding $\mathrm{H} 2$ - at the stage when stimuli are appraised as stressors, no evidence was uncovered supporting $\mathrm{H} 2$ that strong-SOC persons will be more likely to define a stressor as benign or irrelevant, to feel confident that the tension will quickly dissipate. Indeed, after considering it extensively, Antonovsky concluded that primary appraisal is relatively unimportant to the subject of coping because even if a strongSOC person is advantaged, life is filled with stressors that cannot be shrugged aside. We may conclude that $\mathrm{H} 2$ is perhaps testable, but not very interesting.

Regarding H3 - Antonovsky believed that the strongSOC person is more likely to appraise a stressor as (a) happier, (b) less conflictful or (c) less dangerous than one with a weak SOC. I discovered no study intending to measure all three appraisal outcomes. But Brady's (2017) findings in the USA on challenge, hindrance and threat appraisal are consistent with the predictions of $\mathrm{H} 3$, and all three studies by Braun-Lewehsohn and her colleagues (2011, 2018, 2019) provide support for the danger dimension in $\mathrm{H} 3$.

So, there is some evidence supportive of $\mathrm{H} 3$, but only indirectly so. The measures used by Brady (2017) and BraunLewehsohn and colleagues (ibid) were not selected explicitly to test H3. But it may be that indirect tests are all that can be expected. Antonovsky's writings about pathways connecting the SOC and health-related behaviour have not aroused much interest in the research community, for reasons already discussed in the Introduction. This is as true for his writings underlying $\mathrm{H} 4, \mathrm{H} 5$ and $\mathrm{H} 6$ as for $\mathrm{H} 3$.

Regarding H4, I briefly summarise what was stated earlier in this chapter. No research relevant to a test of $\mathrm{H} 4$ was uncovered in a literature search conducted for this chapter. Besides needing data on available GRRs and SRRs and those used in the past to address stressors, a researcher would also need to make judgements about the most appropriate resource or combination of resources in each respondent's armamentarium that the respondent could have called on in the face of given stressors. It is hard to conceive a practical research methodology that would facilitate collecting the needed data. We must conclude that such studies are infeasible, or at last, too demanding to be worth the effort to investigate $\mathrm{H} 4$.

Regarding H5, there is more evidence relevant to this hypothesis alone than for all the other five hypotheses taken together. In studies from Australia, New Zealand, Chile, Poland, the Netherlands, Sweden and Hong Kong, the findings were consistent. Strong-SOC respondents faced with stressors were significantly more likely than weak-SOC respondents to engage in adaptive coping and were significantly less likely to engage in maladaptive coping. The issue of quite selective study samples deserves some discussion. The Australian, New Zealand and Chilean samples were oral health professionals (Gambetta-Tessini et al., 2016). The Polish samples were youth in probation centres (Konaszewski \& Kwadrans, 2020) and the elderly and surgery patients (Krok, 2016; Kotowska \& Weber-Nowakowska, 2019; Andruszkiewicz et al., 2017). The Dutch sample was composed of type 2 diabetes mellitus patients (Polhuis et al., 2020), the Swedish sample was elderly chronically ill patients (Kristofferzon et al., 2018) and the Hong Kong sample were composed of older women undergoing menopausal transition (Ngai, 2019).

What is needed, therefore, is research with populationbased samples that crosscut society. Antonovsky was adamant that salutogenic processes were equally relevant in all persons regardless of age, sex, culture, societal position or the severity and acuteness of their stressor experiences. It is the 'universality' of salutogenesis that distinguishes the salutogenic model from the resilience model of coping:

\footnotetext{
The special interest of resilience scholarship is to assist people living in particularly adverse conditions to do well. Adverse conditions in this sense are exemplified by the experience of poverty, unemployment, violence, crime, family breakdown, and substance abuse. In salutogenesis scholarship, extreme conditions like this cause deep consternation, but the main thrust of the theory is the notion that all people live in the rough and tough river of life from birth to death. (Mittelmark, 2021)
}

Finally, H6 has attracted little attention from salutogenesis researchers. It posits that through the experience of feed- 
back, learning occurs, facilitating the acquisition of GRRs and SRRs, strengthening the SOC, which encourages adaptive coping, which in turn supports health-promoting behaviour. In other words, feedback processes are held by Antonovsky to be essential for salutogenic development. The research discussed earlier by Pijpker et al. (2018) shows that the study of feedback processes in salutogenesis is feasible. Two health promotion priorities seem evident for H6: research is needed on how people can be encouraged to elicit useful feedback, and research is called for on how they can be helped to learn from feedback.

Intervention research is needed with a focus on the tertiary stressor appraisal stage, to enhance feedback and learning processes that strengthen GRRS and fortify the SOC:

- boost skill at eliciting and assessing feedback

- learn to be more attentive to signais about how one is coping

- improve judgement and skill on how and when to alter course

\section{A Role for Health Promotion}

What is the role for health promotion, in the presence of an uncountable number of stress management programmes, advice columns in magazines and newspapers and bestselling books? Health promotion's role is not to add yet more to the plethora of advice on offer. Instead, can we not conduct and apply research on integrating adaptive stimulus and stressor appraisal skills into the home, neighbourhood, educational, work, worship and recreation settings? As many chapters in this handbook testify, it is feasible to integrate health promotion practice into community settings wherein health is not the primary concern, such as schools and workplaces. Therefore, the call here is for health promotion research and practice that fosters a strong-SOC pattern of stressor appraisal in communities generally. This is suggested as an adjunct to, and not a replacement for, SOC strengthening as discussed in other parts of this handbook.

\section{Moving Forward}

As mentioned in the Introduction, Antonovsky did not use the term 'hypothesis' in stating his predictions about how the SOC affects stimulus appraisal. Why are his predictions cast - by this author - as hypotheses? The aim is to elevate researchers' appreciation of stimulus and stressor appraisal as Antonovsky's little-tested answer to the questions posed at the beginning:

- How does the SOC concept link to coping behaviour?
- What are the mechanisms that make the connection?

- What is the black box between?

Antonovsky's absorbing proposals have been discussed in this chapter, and some empirical findings support his contentions. Yet, inevitably, I conclude as the reader might expect - more research is needed. Even more pointedly, salutogenesis researchers should increase their attention to stressor appraisal, action and reaction processes, both conscious and subconscious. We should develop, test and disseminate interventions to help people improve their capacity to engage in adaptive stressor appraisal, as we are all compelled to swim in the river of life - in its constant stream of challenges.

\section{References}

Aldwin, C. M., \& Park, C. L. (2004). Coping and physical health outcomes: An overview. Psychology \& Health, 19(3), 277-281.

Amirkhan, J. H., \& Greaves, H. (2003). Sense of coherence and stress: The mechanics of a healthy disposition. Psychology and Health, 18(1), 31-62.

Andruszkiewicz, A., Basińska, M. A., Felsmann, M., Banaszkiewicz, M., Marzec, A., \& Kędziora-Kornatowska, K. (2017). The determinants of coping with pain in chronically ill geriatric patients-the role of a sense of coherence. Clinical Interventions in Aging, 12, 315-323.

Antonovsky, A. (1979). Health, stress, and coping. Jossey-Bass.

Antonovsky, A. (1986). Intergenerational networks and transmitting the sense of coherence. In N. Datan, A. L. Green, \& H. W. Reese (Eds.), Life-span developmental psychology: Intergenerational relations (pp. 211-222). Lawrence Erlbaum Associates.

Antonovsky, A. (1987). Unraveling the mystery of health: How people manage stress and stay well. Jossey-Bass.

Antonovsky, A. (1990a). Pathways leading to successful coping and health. In M. Rosenbaum (Ed.), Learned resourcefulness: On coping skills, self-control, and adaptive behavior (pp. 31-63). Springer Publishing.

Antonovsky, A. (1990b). Personality and health: Testing the sense of coherence model. Personality and Disease, 7, 155-177.

Antonovsky, A. (1990c). A somewhat personal odyssey in studying the stress process. Stress Medicine, 6(2), 71-80.

Antonovsky, A. (1992). Can attitudes contribute to health? The Journal of Mind-Body Health, 8(4), 33-49.

Antonovsky, A. (1993). The structure and properties of the sense of coherence scale. Social Science \& Medicine, 36(6), 725-733.

Bauer, G. F., \& Jenny, G. J. (2007). Development, implementation and dissemination of occupational health management (OHM): Putting salutogenesis into practice. In J. Houdmont \& S. McIntyre (Eds.), Occupational health psychology: European perspectives on research, education and practice (pp. 219-250). ISMAI Publications.

Brady, L. L. (2017). The role of sense of coherence in stressor appraisal. The University of Tennessee at Chattanooga. https://doi. org/10.1037/e507482017-001; Corpus ID: 151688631.

Braun-Lewensohn, O., Sagy, S., \& Roth, G. (2011). Coping strategies as mediators of the relationship between sense of coherence and stress reactions: Israeli adolescents under missile attacks. Anxiety, Stress, \& Coping, 24(3), 327-341. 
Braun-Lewensohn, O., \& Al-Sayed, K. (2018). Syrian adolescent refugees: How do they cope during their stay in refugee camps? Frontiers in Psychology, 9, 1258. https://doi.org/10.3389/fpsyg.2018.01258

Braun-Lewensohn, O., Abu-Kaf, S., \& Al-Said, K. (2019). Women in refugee camps: Which coping resources help them to adapt? International Journal of Environmental Research and Public Health, 16(20), 3990. https://doi.org/10.3390/ijerph16203990

Cavanaugh, M. A., Boswell, W. R., Roehling, M. V., \& Boudreau, J. W. (2000). An empirical examination of self-reported stress among U.S. managers. Journal of Applied Psychology, 85, 65-74.

Cheng, C., \& Cheung, M. W. (2005). Cognitive processes underlying coping flexibility: Differentiation and integration. Journal of Personality, 73(4), 859-886.

Eriksson, M., \& Lindström, B. (2006). Antonovsky's Sense of Coherence Scale and the relation with health: A systematic review. Journal of Epidemiology \& Community Health, 60(5), 376-381.

Eriksson, M., \& Lindström, B. (2007). Antonovsky's sense of coherence scale and its relation with quality of life - A systematic review. Journal of Epidemiology and Community Health, 61(11), 938-944.

Feldman, P. J., Cohen, S., Hamrick, N., \& Lepore, S. J. (2004). Psychological stress, appraisal, emotion and cardiovascular response in a public speaking task. Psychology \& Health, 19(3), 353-368.

Gambetta-Tessini, K., Mariño, R., Morgan, M., \& Anderson, V. (2016). Coping strategies and the salutogenic model in future oral health professionals. BMC Medical Education, 16(1), 1-8.

Konaszewski, K., Kolemba, M., \& Niesiobędzka, M. (2019). Resilience, sense of coherence and self-efficacy as predictors of stress coping style among university students. Current Psychology. https://doi. org/10.1007/s12144-019-00363-1

Konaszewski, K., \& Kwadrans, Ł. (2020). Sense of coherence and resilience for coping with stress in the group of juveniles referred to probation centres by family courts. Kwartalnik Pedagogiczny, 1(255), 134-159.

Kotowska, J., \& Weber-Nowakowska, K. (2019). Sense of coherence, its meaning and coping with stress among people after orthopedic surgery. Journal of Education, Health and Sport, 9(4), 459-467.

Kristofferzon, M. L., Engström, M., \& Nilsson, A. (2018). Coping mediates the relationship between sense of coherence and mental quality of life in patients with chronic illness: A cross-sectional study. Quality of Life Research, 27(7), 1855-1863.

Krok, D. (2016). Sense of coherence mediates the relationship between the religious meaning system and coping styles in Polish older adults. Aging \& Mental Health, 20(10), 1002-1009.

Lazarus, R. S., \& Cohen, J. B. (1977). Environmental stress. In I. Altman \& J. E. Wohlwill (Eds.), Human behavior and environment (Vol. 2). Plenum.
Lazarus, R. S. (1984). Puzzles in the study of daily hassles. Journal of Behavioral Medicine, 7, 375-389.

Lazarus, R. S., \& Folkman, S. (1984). Stress, appraisal, and coping. Springer.

Mittelmark, M. B., Sagy, S., Eriksson, M., Bauer, G. F., Pelikan, J. M., Lindström, B., \& Arild Espnes, G. (2017). The Handbook of Salutogenesis. Springer Nature. E-book, open access.

Mittelmark, M. B. (2021). Resilience in the salutogenic model of health. In M. Ungar (Ed.), Multisystemic resilience. Oxford University Press. https://doi.org/10.1093/oso/9780190095888.003.0009

Ngai, F. W. (2019). Relationships between menopausal symptoms, sense of coherence, coping strategies, and quality of life. Journal of the North American Menopause Society, 26(7), 758-764.

Pijpker, R., Vaandrager, L., Bakker, E. J., \& Koelen, M. (2018). Unravelling salutogenic mechanisms in the workplace: The role of learning. Gaceta Sanitaria, 32, 275-282.

Polhuis, C. M. M., Vaandrager, L., Soedamah-Muthu, S. S., \& Koelen, M. A. (2020). Salutogenic model of health to identify turning points and coping styles for eating practices in type 2 diabetes mellitus. International Journal for Equity in Health, 19, 1-20.

Scherer, K. R., Schorr, A., \& Johnstone, T. (2001). Appraisal processes in emotion. Oxford University Press.

Searle, B. J., \& Auton, J. C. (2015). The merits of measuring challenge and hindrance appraisals. Anxiety, Stress, and Coping, 28(2), 121-143.

Sideridis, G. D. (2006). Coping is not an 'either' 'or': The interaction of coping strategies in regulating affect, arousal and performance. Stress and Health, 22(5), 315-327.

Silverstein, M., \& Heap, J. (2015). Sense of coherence changes with aging over the second half of life. Advances in Life Course Research, 23, 98-107.

Super, S., Wagemakers, M. A. E., Picavet, H. S. J., Verkooijen, K. T., \& Koelen, M. A. (2016). Strengthening sense of coherence: Opportunities for theory building in health promotion. Health Promotion International, 31(4), 869-878.

Tuckey, M. R., Searle, B. J., Boyd, C. M., Winefield, A. H., \& Winefield, H. R. (2015). Hindrances are not threats: Advancing the multidimensionality of work stress. Journal of Occupational Health Psychology, 20(2), 131-147.

Wechkunanukul, K., Grantham, H., \& Clark, R. A. (2017). Global review of delay time in seeking medical care for chest pain: An integrative literature review. Australian Critical Care, 30(1), 13-20.

Weiner, B. (2010). The development of an attribution-based theory of motivation: A history of ideas. Educational Psychologist, 45, 28-36.

Open Access This chapter is licensed under the terms of the Creative Commons Attribution 4.0 International License (http://creativecommons. org/licenses/by/4.0/), which permits use, sharing, adaptation, distribution and reproduction in any medium or format, as long as you give appropriate credit to the original author(s) and the source, provide a link to the Creative Commons license and indicate if changes were made.

The images or other third party material in this chapter are included in the chapter's Creative Commons license, unless indicated otherwise in a credit line to the material. If material is not included in the chapter's Creative Commons license and your intended use is not permitted by statutory regulation or exceeds the permitted use, you will need to obtain permission directly from the copyright holder. 